\title{
Research Quality Evaluation in Social Sciences: The Case of Criteria on the Conditions and Requirements for Academic Promotion in Serbia, Slovenia and Montenegro
}

\author{
Stevo Popovic ${ }^{1,2}$, Sanja Pekovic ${ }^{2,3}$, Radenko M. Matic ${ }^{4}$ \\ Affiliations: 'University of Montenegro, Faculty for Sport and Physical Education, Niksic, Montenegro, ${ }^{2}$ Montenegrin \\ Academy of Sciences and Arts, Center of Young Scientists, Podgorica, Montenegro, ${ }^{3}$ University of Montenegro, Faculty \\ of Tourism and Hotel Management, Kotor, Montenegro, ${ }^{4}$ University of Novi Sad, Faculty of Sport and Physical \\ Education, Novi Sad, Serbia
}

Correspondence: S. Popovic, University of Montenegro, Faculty for Sport and Physical Education, Narodne omladine bb, 81400 Niksic, Montenegro, email: stevop@ucg.ac.me

ABSTRACT The primary goal of the present paper is to analyse and compare the criteria on the conditions and requirements for academic promotion in three countries: Serbia, Slovenia and Montenegro. The University of Novi Sad, the University of Ljubljana, and the University of Montenegro were selected to be subjects in this study. The sources used for the analyses in this study were the official criteria on the condition and requirements for academic promotion at the abovementioned universities. The authors used a descriptive method with the consulting of competent sources and personal experiences. First, it is interesting to note that the universities in Serbia and Slovenia follow official documents at two levels: one at the national level issued by the relevant higher education council/agency and the second at the university level issued by the senate of each university, whose criteria are more strict in terms of quantitative requirements. However, this is not the case in Montenegro, where universities follow only the national criteria in the research quality evaluation. In each country, evaluation exercises usually recognize three fields, one of which is social sciences and humanities, which is concerned with an entire range of interdisciplinary and multidisciplinary scientific areas. Comparing the minimum standards for the appointment of university teachers, it is essential to highlight that Slovenian regulations are the most demanding, especially with regards to quantitative criteria, while Serbian and Montenegrin criteria are similar to each other; however, it is necessary to highlight that Montenegrin regulations contain some unusual criteria, such as the requirement that scientific research work must be achieved through one single-author paper published in an international journal for promotion to academic titles at all three levels (assistant, associate and full professor) in social sciences and humanities; however, this is not the case in other academic fields.

KEY WORDS evaluation, research, social, science, Yugoslavia

@MJSSMontenegro

RESEARCH QUALITY EVALUATION IN SOCIAL SCIENCES

http://mjssm.me/?sekcija=article\&artid=183

\section{Introduction}

The evaluation of the quality of scientific research has always been a crucial issue in the development process of every society (Aksnes \& Taxt, 2004; Peruginelli, \& Faro, 2018; Zuccala, 2018). Investing in scientific research has opened up new opportunities for every society and, through innovative products and services it has produced, has influenced every facet of global society. Since the time of the ancient civilizations, such as Greece and Rome, people have recognized the benefits of the results of scientific research. Even then, they carried out, in a very skilful way, the evaluation of the quality of research because they were aware that such activities would raise the process of it to a much higher level. 
Today, with the explosion of digitization, new forms of research data exchange have begun to appear. The processes of research itself are changing rapidly, multidisciplinary approaches are emerging, and new research projects do not resemble those of ancient Greece and Rome - they do not even look like research projects that were carried out only a decade or two ago (Harzing \& Alakangas, 2016; Harzing, 2019; Moed, Burger, Frankfort, \& Van Raan, 1985; Narin \& Hamilton, 1996). Contemporary research projects are based on the increasing specialization in the field of digitization, and such a specialization significantly changes the work of researchers, not only those from natural and technical sciences, but also those from the social sciences and humanities (Jokic, Mervar, \& Mateljan, 2019; Singleton, Straits, \& Straits, 1993). Nowadays, researchers in the field of, for example, sport sciences, even though they are fundamentally oriented towards social sciences, must possess skills and knowledge, not only from practical areas of sports science, such as physical activity and sports, but also from areas such as computer science, knowledge of specific foreign language and skills of handling the various hardware and software that are necessary to conduct research in the best possible way (Popovic, 2018; Thelwall, 2018).

It is necessary that the aforementioned matter be taken responsibly in the evaluation process. The results of scientific research represent an output that is of interest to a broad community (Abramo, Cicero, \& D'Angelo, 2012), and not only researchers who implement and read them but all interested parties, primarily other researchers, research organizations and research financiers (Lohr, 2004). In order for the research to be of high quality and serve the purpose for which it was launched, it is necessary to make this process as open and transparent as possible. Also, the process of evaluating the quality of research must be free of any agenda that could jeopardize the freedom of thought and creativity of researchers (Peruginelli \& Faro, 2018).

Even though the modern era offers many opportunities for the further development of science, it still has significant deficiencies, which are reflected in an unfair evaluation of research (Elango, Kozak, \& Rajendran, 2019), which is the primary source of frustration and potential threats to the further development of science. Therefore, it is challenging to obtain a generally accepted solution (Allen, Jones, Dolby, Lynn, \& Walport, 2009). Strongly opposed specific structures, on the one hand, support a traditional approach of evaluating research through a qualitative assessment of personal or institutional reputation, the relevance of projects, the prestige of journals, and similar factors, while on the other, there are those who support an alternative approach to the evaluation of research (Peruginelli, \& Faro, 2018), which is gaining increasing attention from the scientific public, because it is based on seemingly objective quantitative indicators, such as the number of citations, various bibliometric factors, and the journal impact factor (Chandler, 2019). Since there was no consensus, in some countries, written standards have begun to appear, which represent predetermined rules, and the research results are being evaluated according to them.

As the aforementioned rules represented an agreement between varying members of the scientific community, which aimed to establish criteria for the evaluation of scientific research, it was expected that they would differ among the social communities, depending on the needs and willingness of individual communities to compromise (Abramo, D’Angelo, \& Reale, 2019; Vieira, Cabral, \& Gomes, 2014). However, a gap remains between scientific fields, as it was difficult to determine the same criteria that would meet the primary needs for the evaluation of research in various fundamental scientific fields. The results of the research in the natural-mathematical and technical fields could not be evaluated in the same way as the results from the social sciences and humanities (Taubes, 1993), primarily because of the particular traditions and nature of research within those fields. For this reason, specific criteria for the evaluation of research in various fundamental scientific areas began to appear.

Recognition of scientific quality is not only necessary for the further motivation of each researcher to deal with science, but also the necessary key to open the door towards new research projects so that the research process never stops (Abramo, D’Angelo, \& Rosati, 2015). Furthermore, it is essential that researchers not be exclusively focused on the set criteria. They should turn to the essential goals of their research activities and concentrate on, first of all, attracting certain monetary funds from public institutions, domestic and international donors, necessary for the unhindered testing of set research questions, then creating and supporting a scientific authority in their social community and internationally, i.e., obtaining specific tangible and intangible merits for themselves and for the organization for which they work (Seglen, 1998).

The criteria above, in the form of specific measuring instruments, have found wide application at higher education institutions around the world, where the rules are clearly set for the further promotion of teaching and research personnel (Abramo, 2018). Many debates on this topic are on-going, and the above-mentioned instruments are always the subject of criticism and pressure from certain structures to be changed. Consequently, the most critical topics in the research quality evaluation in the social sciences are the choices and definitions of criteria evaluation; the main goal of the present paper is thus to analyse and compare the criteria on the conditions and requirements for academic promotion in three countries: Serbia, Slovenia and Montenegro, which were jointly developed within the former Yugoslavia, and have continued their journeys since the beginning of the 1990s.

\section{Methods}

The University of Novi Sad, the University of Ljubljana, and the University of Montenegro were selected to be subjects in this study. The University of Novi Sad was established in 1960: It is located in Novi Sad, the second biggest city in Serbia, and has over 50,000 students and 5,000 employees (University of Novi Sad, 2019). The University of Ljubljana was established in 1919. It is located in Ljubljana, the capital of Slovenia and has over 40,000 students and 5,600 employees (University of Ljubljana, 2019). The University of Montenegro was established in 1974. It is located in Podgorica, the capital of Montenegro and has over 21,000 students and 1,200 employees (University of Montenegro, 2019). 


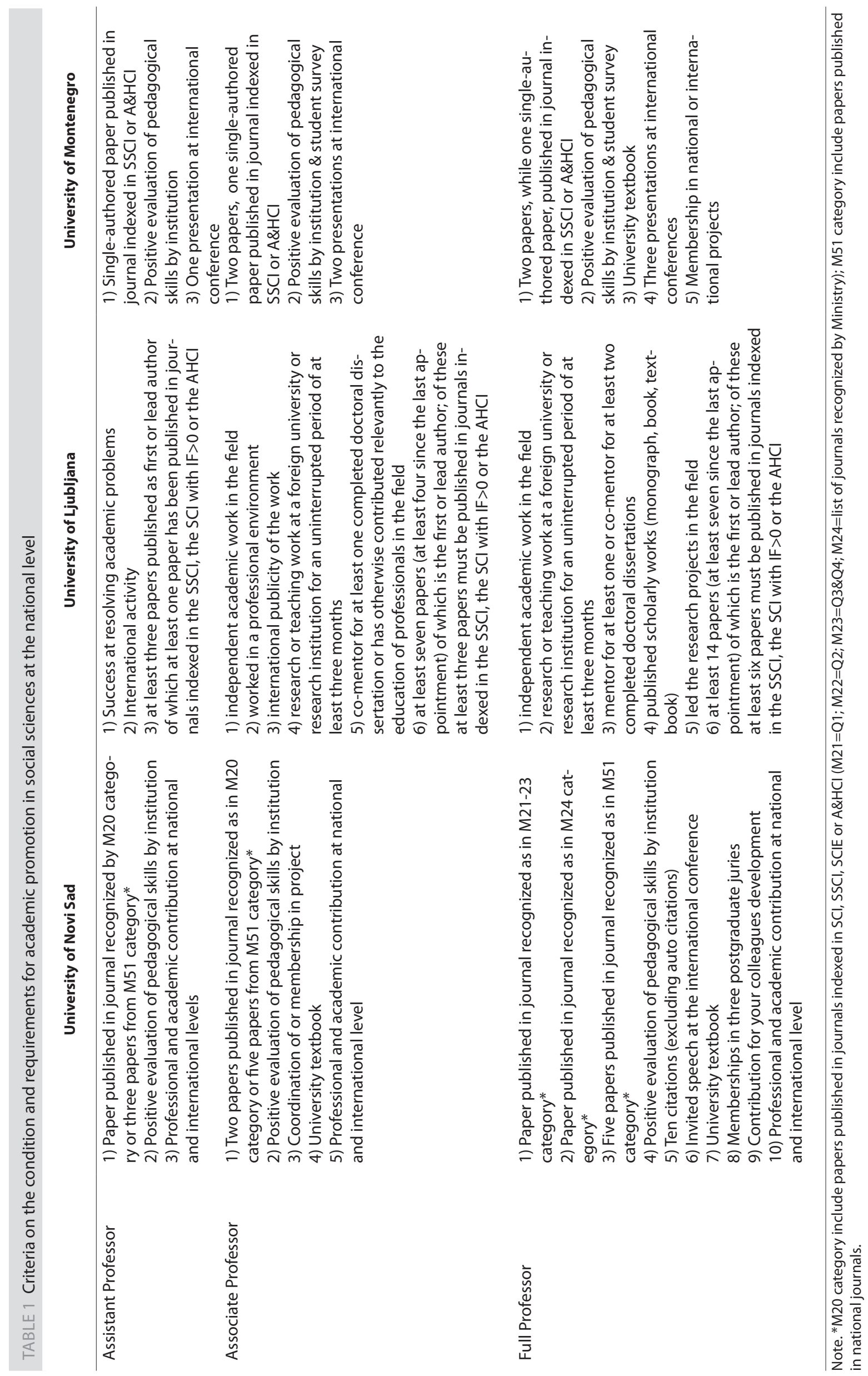


The sources used for the analyses in this study were the following documents:

1. Minimum standards for the appointment of university teachers issued by National Council for Higher Education of the Republic of Serbia (Minimum standards for the appointment of university teachers, 2016), and Minimum standards for the appointment of university teachers at University of Novi Sad issued by the Senate of the University of Novi Sad (Minimum standards for the appointment of university teachers at University of Novi Sad, 2018),

2. Minimum standards for the appointment of higher education teachers, researchers and faculty assistants at higher education institutions issued by the Council of the Slovenian Quality Assurance Agency for Higher Education in Slovenia (Minimum Standards for the Appointment of Higher Education Teachers, Researchers and Faculty Assistants at Higher Education Institutions, 2010) and Criteria for appointment to the titles of university teacher, researcher and associate at the University of Ljubljana issued by the Senate of the University of Ljubljana (Criteria for Appointment to the Titles of University Teacher, Researcher and Associate at the University of Ljubljana, 2011),

3. Criteria on the conditions and requirements for promotion to academic titles issued by the Council for Higher Education in Montenegro (Criteria on the Conditions and Requirements for Promotion to Academic Titles, 2016).

The authors used a descriptive method with the consulting of competent sources and personal experience to analyse and compare the criteria on the condition and requirements for academic promotion in three countries: Serbia, Slovenia, and Montenegro.

\section{Results}

First, it is interesting to note that the universities in Serbia and in Slovenia follow the official documents at two levels: one at the national level issued by a higher education council/agency, and the second, at the university level issued by the senate of each university, whose criteria are stricter in terms of quantitative requirements. However, this is not the case in Montenegro, where universities follow only the national criteria in the research quality evaluation. In Montenegro and Serbia, evaluation exercises usually recognized three fields, one of which is the social sciences and humanities, which cover a vast range of interdisciplinary and multidisciplinary scientific areas. In contrast, in Slovenia, evaluation exercises recognized two fields, which means it separates the field of arts from the rest of the academic fields.

The results of this study are presented in two tables. Table 1 describes the criteria for the conditions and requirements for academic promotion in social sciences at the national level; Table 2 describes the criteria for the conditions and requirements for academic promotion in the social sciences at the institutional level. Even though all the criteria seem similar at first glance, the qualitative and quantitative differences reflect the differences in quality that are visible on the prestigious world rankings of universities. Specifically, the smallest differences in quantitative requirements, which clearly exist between the analysed universities, cause significant differences in ranking at the global level (Academic Ranking of World Universities, 2018). If, for example, a university has a requirement that an academic have one paper published in journals indexed in SCI/SSCI/SCIE/AHCI, and the university has 1000 employed teachers or researchers, this is reflected in 1000 published papers. This detail significantly raises the rating of each university, and any realistic scaling is multiply beneficial for both individuals and for the institution.

It is interesting that at the University of Ljubljana, which has been among the top 500 ranked universities in the Shanghai university ranking list for years, quantitative requirements were significantly higher compared to the other two analysed universities, which, at the overall institutional level, were not included on this list. In contrast, the University of Novi Sad has more transparent and more precise criteria, especially regarding the social sciences, and the results are expected to be better. For example, one of the faculties that belong to the social group, the Faculty of Sport and Physical Education from the university above, was ranked among the top 500 universities in the Shanghai University ranking list within its specific field (Shanghai Ranking's Global Ranking of Sport Science Schools and Departments, 2018). The University of Montenegro still lacks the aforementioned acknowledgements for social sciences, mostly because some quantitative requirements have been established in the latest criteria that are not in line with any good European example. It is noteworthy that a scientist in the social sciences is required to publish a paper as an autonomous author. For example, in sports science, such a requirement is against the basic principles, based on which scientists have grown and developed into serious scientific workers, through collaborative work.

Furthermore, there is another limitation, which states that a prospective paper needs to be published exclusively in a journal indexed in the SSCI index. This requirement significantly reduces the number of available journals, especially for scientists coming from multidisciplinary areas, such as sport science, but also tourism, architecture, and other fields. Sport scientists are usually unable to publish the results of their research in "strictly social" journals, primarily because of the multidisciplinary nature of their research; sometimes they encounter a situation in which academic promotions are brought into question because of the reckless criteria established by the Council for Higher Education of Montenegro, but obviously without the extensive and careful analysis that the social sciences need.

Based on everything previously said, it is clear that the research quality evaluation is one of the crucial issues that can significantly improve the quality of research, but also the rating and visibility of both scientists and institutions at the international level. Therefore, it is necessary to carefully and critically analyse the current criteria, because that is the first step in the process of determining criteria that would, in the best manner, serve to upgrade scientific research, especially in the social sciences, and not to the interests of individuals and institutions, as seems to be the case in determining the analysed criteria in Montenegro. 


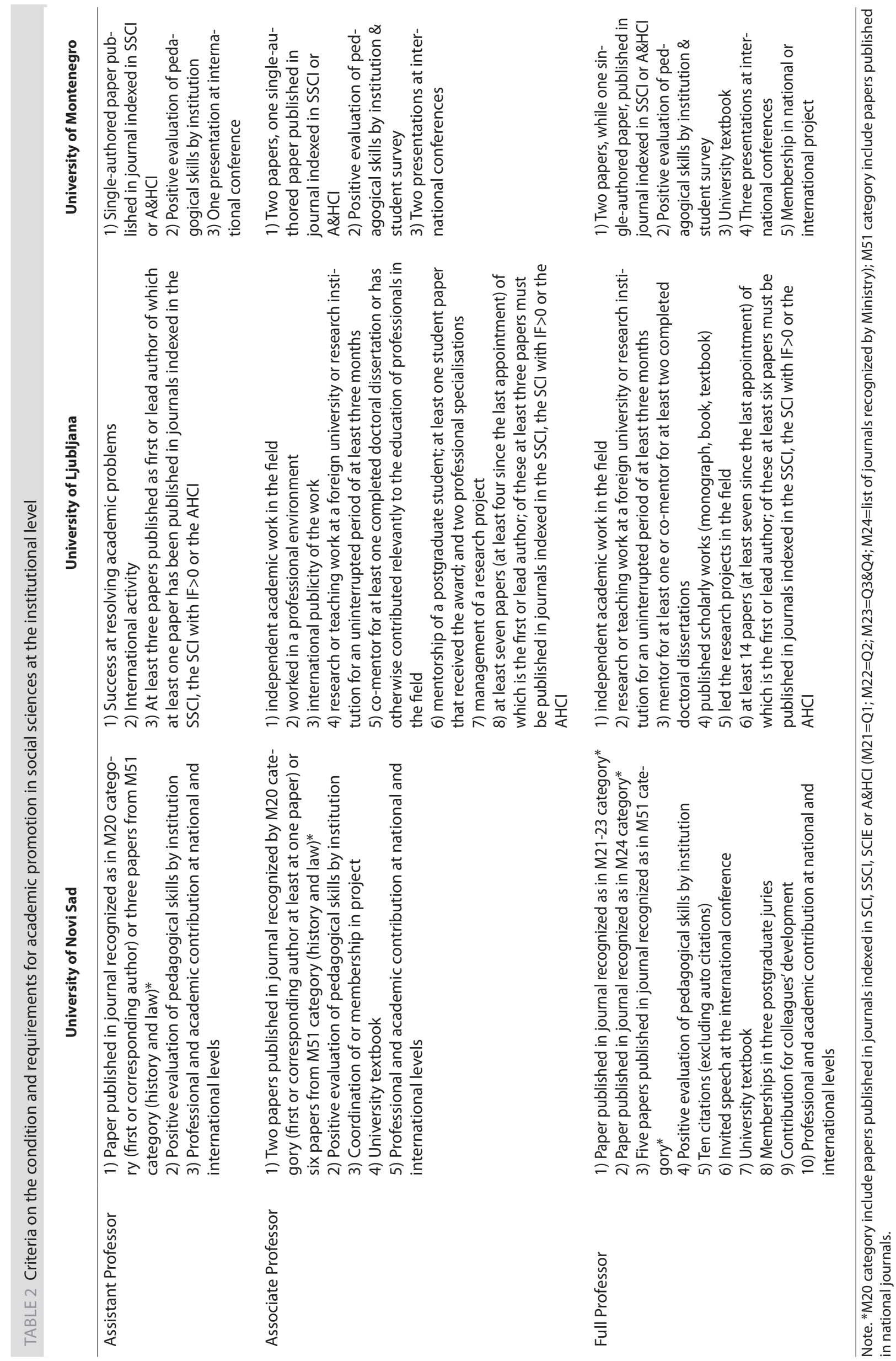




\section{Discussion}

As previously mentioned, a large number of debates on research evaluation are ongoing, and the current criteria are always the subject of criticism and pressure of certain structures to be changed. However, comparing the minimum standards for the appointment of university teachers, it is necessary to highlight that Slovenian regulations are the most demanding (Minimum Standards for the Appointment of Higher Education Teachers, Researchers and Faculty Assistants at Higher Education Institutions, 2010), especially with regard to their quantitative criteria, while the Montenegrin and Serbian criteria (Criteria on the Conditions and Requirements for Promotion to Academic Titles, 2016; Minimum standards for the appointment of university teachers, 2016) are quite similar; however, it is essential to highlight that Montenegrin regulations contain some unusual criteria, such as the requirement that scientific research work must be achieved through one single-authored paper published in an international journal for promotion to academic titles at all three levels (assistant, associate and full professor) in social sciences and humanities. It is essential to highlight that this is not the case in two other fields (natural and technical sciences and arts). For example, if one young researcher from the field of sports science in Montenegro wants to be promoted to assistant professor, he/she needs to publish at least one paper in the journal that is indexed in the Social Science Citation Index (SSCI) database as a single-authored paper. This is definitely against the foundational principles of science, as collaborative work is the driving force that develops the scientific process and reaches the relevant conclusions based on joint discussion.

In contrast, a young researcher can promote him/herself in Serbia much more easily from the quantitative point of view, as he/she does not need a single-authored paper, but must be the leading author of one paper published in the journal recognized as belonging to the M20 category (first or corresponding author). This means he/she might publish the paper in each database from Web of Science (SCI/SCIE/SSCI// AHCI) that has an impact factor or in the M24 category, which represents the yearly list of journals announced by the Ministry in Serbia (Minimum standards for the appointment of university teachers at University of Novi Sad, 2018).

The Slovenian example is more demanding, because the young researcher from the field of sports science needs to publish at least three papers as first or lead author, of which at least one paper its in journals indexed in the SSCI, the SCI with IF $>0$ or the AHCI (Criteria for Appointment to the Titles of University Teacher, Researcher and Associate at the University of Ljubljana, 2011). The Slovenian regulations purposely excluded the SCIE database as it contains a wider range of journals, but did not make a meaningless decision to limit all the researchers from social sciences to publishing their mandatory paper in the journals indexed just in SSCI database, as is the case in Montenegro. The Montenegrin example has limited many of multidisciplinary areas within the social sciences, including sport science.

The issue mentioned in the previous paragraph is not the only one in the Montenegrin Criteria on the Conditions and Requirements for Promotion to Academic Titles, and Article 14, to be criticized. Specifically, the criteria state that the previous criteria (from 2004) prescribed for promotion to academic titles shall be applied to people who had been promoted to academic titles until the Law on Higher Education ("Official Gazette of Montenegro", no. 44/14 and 47/15) entered into force, for the subsequent promotion to an academic title. This means that it is much easier to be promoted to associate and full professor at the University of Montenegro than to assistant professor, as the requirements from the previous criteria are much easier. This fact significantly discriminates against younger researchers, mostly because they need to satisfy much stronger requirements and, theoretically, be supported by senior colleagues, who did not need to satisfy the same requirements. This fact clearly indicates that a change of criteria should be considered as quickly as possible, mostly because the current rules might discourage the young researcher and direct them out of academia. In contrast, such issues are not present in the criteria in Slovenia and Serbia, but the debates on research evaluation should be continued in all three countries; furthermore, the current criteria should be the subject of criticism, all in order to develop an international ranking of the institutions.

It is essential to highlight that the limitation of this study is reflected in the method applied. A descriptive method with consulting of competent sources and personal experience is used to analyse and compare the criteria in the selected countries. However, some more rigorously scientific methods would improve some further investigations in the area. Nevertheless, the limitations of this study are that it is analysed just mandatory requirements from the criteria in all three countries; however, the other requirements need to be reviewed carefully too, especially those contained in the methodology for the international ranking of the universities.

From all the above-mentioned in this study, it is easy to conclude that research evaluation in social sciences is an area that is still developing and it is vital to involve all stakeholders in the future that can help in any form to reach as best criteria that are in line with international standards and meet domestic needs. For the further studies, it is crucial to take into consideration the limitation of this study and carefully analyse the difference among the various field of studies, especially those of the social sciences that have some natural or technical components with their multidisciplinary approach, such as sports science, tourism, architecture, among others.

In addition, it is highly recommended to take a methodological approach that can help to improve research processes at the national level, but also improve recognition and visibility at the international level; academic ranking of global universities is the best example of this.

It is also recommended to combine qualitative and quantitative methods, to ensure that the exclusively quantitative conclusions based on statistics do not force us in the wrong direction, and to keep constant criticism 
and pressure on certain structures that are making decisions in the area of research evaluation, such as national councils of higher education, senates of universities, as well as all other relevant institutions that can influence the development of this area.

\section{Acknowledgement}

This paper has been written within national project under the title "Quality of Research in Social Science and Humanities" that was approved by Ministry of Science in Montenegro (No.01- 2589/2 from 11 December 2017), as well as in line with the COST Action's objectives (CA15357).

\section{REFEREN CES}

Abramo, G. (2018). Revisiting the scientometric conceptualization of impact and its measurement. Journal of Informetrics, 12(3), 590-597. doi: 10.1016/j.joi.2018.05.001

Abramo, G., Cicero, T., \& D'Angelo, C. A. (2012). The dispersion of research performance within and between universities as a potential indicator of the competitive intensity in higher education systems. Journal of Informetrics, 6(2), 155-168. doi: 10.1016/j.joi.2011.11.007

Abramo, G., D’Angelo, C. A., \& Rosati, F. (2015). The determinants of academic career advancement: evidence from Italy. Science and Public Policy, 42(6), 761-774. doi: 10.1093/scipol/scu086

Abramo, G., D’Angelo, C.A. \& Reale, E. (2019). Peer review versus bibliometrics: Which method better predicts the scholarly impact of publications? Scientometrics, 1-18. doi: 10.1007/s11192-019-03184-y

Academic Ranking of World Universities. (2019). Shanghai, Shanghai Ranking Consultancy. Reached on 10.2.2019 from website: http://www.shanghairanking.com/ARWU2018.html.

Aksnes, D. W., \& Taxt, R. E. (2004). Peer reviews and bibliometric indicators: A comparative study at Norvegian University. Research Evaluation, 13(1), 33-41. doi: 10.3152/147154404781776563

Chandler, V. (2019). Identifying emerging scholars: seeing through the crystal ball of scholarship selection committees. Scientometrics, 120(1), 39-56. doi: 10.1007/s11192-019-03120-0

Criteria for Appointment to the Titles of University Teacher, Researcher and Associate at the University of Ljubljana. (2011). Ljubljana, University of Ljubljana. Reached on 25.10.2011 from website: https:// www.uni-lj.si/university/organization_legal_framework_and_reports/statutes_of_ul_and_regulations/2014010714215361/

Criteria on the Conditions and Requirements for Promotion to Academic Titles. (2016). Podgorica, Council of Higher Education. Reached on 16.6.2017 from website: https://www.ucg.ac.me/objava/blog/6/ objava/3745-savjet-za-visoko-obrazovanje-09-09-2016-mjerila-o-uslovima-i-kriterijumima-za-izboru-akademska-zvanja

Elango, B., Kozak, M. \& Rajendran, P. (2019). Analysis of retractions in Indian science. Scientometrics, 119(2), 1081-1094. doi: 10.1007/s11192-019-03079-y

Harzing, A. W., \& Alakangas, S. (2016). Google Scholar, Scopus and the Web of Science: A longitudinal and cross-disciplinary comparison. Scientometrics, 106(2), 787-804. doi: 10.1007/s11192-015-1798-9

Harzing, A.W. (2019). Two new kids on the block: How do Crossref and Dimensions compare with Google Scholar, Microsoft Academic, Scopus and the Web of Science? Scientometrics, 120(1), 341-349. doi: 10.1007/s11192-019-03114-y

Jokic, M., Mervar, A. \& Mateljan, S. (2019). Comparative analysis of book citations in social science journals by Central and Eastern European authors. Scientometrics, 1-25. doi: 10.1007/s11192-019-03176-y

Lohr, K.N. (2004). Rating the strength of scientific evidence: Relevance for quality improvement programs. International Journal for Quality in Health Care, 16(1), 9-18. doi: 10.1093/intqhc/mzh005

Minimum Standards for the Appointment of Higher Education Teachers, Researchers and Faculty Assistants at Higher Education Institutions. (2010). Ljubljana, Slovenian Quality Assurance Agency for Higher Education. Reached on 18.11.2010 from website: https://www.google.com/url?sa=t\&rct=j\&q=\&es$\mathrm{rc}=\mathrm{s} \&$ source $=$ web\& $\mathrm{cd}=10 \& \mathrm{cad}=\mathrm{rja} \& u a c t=8 \& \mathrm{ved}=2$ ahUKEwjfgMP_1a7jAhVOR5oKHYwnBv0QFjAJegQIABAC\&url=http\%3A\%2F\%2Ftest.nakvis.si\%2Fsl-SI\%2FContent\%2FGetFile\%2F130\&us$\mathrm{g}=\mathrm{AOvVaw0ChOB3W7LP0qq1iGnRGbsu}$

Minimum standards for the appointment of university teachers at University of Novi Sad. (2018). Novi Sad, University of Novi Sad. Reached on 9.10 .2018 from website: https://www.elektronika.ftn.uns.ac.rs/ wp-content/uploads/2019/04/UNS_Pravilnik_izbor_u_zvanja_2018.pdf

Minimum standards for the appointment of university teachers. (2016). Belgrade, National Council for Higher Education of the Republic of Serbia. Reached on 24.10.2016 from website: https://www.ucg.ac.me/objava/blog/6/objava/3745-savjet-za-visoko-obrazovanje-09-09-2016-mjerila-o-uslovima-i-kriterijumimaza-izbor-u-akademska-zvanja

Moed, H.F., Burger, W.J.M., Frankfort, J.G., \& Van Raan, A.F.J. (1985). The application of bibliometric indicators: Important field- and time-dependent factors to be considered. Scientometrics, 8(3-4), 177-203. https://doi.org/10.1007/BF02016935

Narin, F., \& Hamilton, K.S. (1996). Bibliometric performance measures. Scientometrics, 36, 293-310. doi: $10.1007 / B F 02129596$

Peruginelli, G., \& Faro, S. (2018). Research Quality Evaluation: The Case of Legal Studies. In A. Bonaccorsi (Ed.), The Evaluation of Research in Social Sciences and Humanities (pp. 103-129). Trento: Springer International Publishing AG. 
Popovic, S. (2018). Research and Writing Development in the Area of Sport Science Publishing in Montenegro. Sport Mont, 16(3), 31-36. doi: 10.26773/smj.181006

Shanghai Ranking's Global Ranking of Sport Science Schools and Departments. (2019). Shanghai, Shanghai Ranking Consultancy. Reached on 10.2.2019 from website: http://www.shanghairanking.com/Special-Focus-Institution-Ranking/Sport-Science-Schools-and-Departments-2018.html\#.

Singleton, R.A., Straits, B.C., \& Straits, M.M. (1993). Approaches to social research. New York: Oxford University Press.

Taubes, G. (1993). Measure for measure in science. Science, 260, 884-886. doi: 10.1126/science.8493516

Thelwall, M. (2018). Microsoft Academic automatic document searches: Accuracy for journal articles and suitability for citation analysis. Journal of Informetrics, 12(1), 1-9. doi: 10.1016/j.joi.2017.11.001

University of Ljubljana. (2019). Ljubljana, University of Ljubljana. Reached on 23.1.2019 from website: https://www.uni-lj.si

University of Montenegro. (2019). Podgorica, University of Montenegro. Reached on 23.1.2019 from website: http://www.ucg.ac.me

University of Novi Sad. (2019). Novi Sad, University of Novi Sad. Reached on 23.1.2019 from website: http:// www.uns.ac.rs

Vieira, E.S., Cabral, J.A.S., \& Gomes, J.A.N.F. (2014). Definition of a model based on bibliometric indicators for assessing applicants to academic positions. Journal of the Association for Information Science and Technology, 65(3), 560-577. doi: 10.1002/asi.22981

Zuccala, A. (2018). Language, Culture and Traversing the Scholarly Evaluation Landscape. In A. Bonaccorsi (Ed.), The Evaluation of Research in Social Sciences and Humanities (pp. 395-411). Trento: Springer International Publishing AG. 